\title{
DIDÁTICA DA EDUCAÇÃO FÍSICA BRASILEIRA: UMA COMPREENSÃO DA PRODUÇÃO CIENTÍFICA
}

\author{
Paulo Carlan \\ Universidade Regional do Noroeste do Estado do Rio Grande do Sul, Ijuí, Rio Grande do Sul, Brasil.
}

Soraya Corrêa Domingues

Universidade Federal de Santa Catarina, Florianópolis, Santa Catarina, Brasil.

\section{Elenor Kunz}

Universidade Federal de Santa Catarina, Florianópolis, Santa Catarina, Brasil.

\begin{abstract}
Resumo
O objetivo deste texto é compreender o tratamento e o papel que a Didática vem assumindo nas práticas pedagógicas da Educação Física escolar, e se a acompanhou as propostas metodológicas críticas. Utilizou-se como método a análise de três artigos científicos, cuja leitura desvelou estruturas conceituais que elucidaram os pressupostos teóricos e didático-metodológicos. Conclui-se, após a interpretação dos artigos científicos, que a Educação Física escolar deve superar o reducionismo técnico-instrumental da Didática e redimensionar seu papel aproximando-se da dimensão pedagógica e epistemológica.

Palavras-chave: Didática - Educação Física Escolar - Produção do Conhecimento.
\end{abstract}

\section{Introdução}

Educação Física brasileira no final dos anos 70 e durante a década de 1980 foi

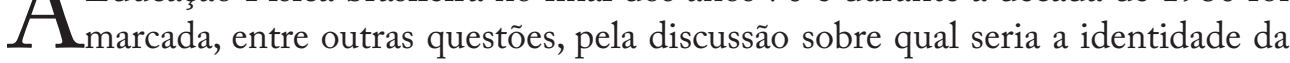
Educação Física, seu campo de saber e seu objeto epistemológico articulador das práticas pedagógicas.

Para Kunz (2003), é inegável que a Educação Física brasileira nas últimas duas décadas alcançou um extraordinário desenvolvimento na produção científica. Por outro lado, ressalva que isto não garantiu efetivamente mudanças das práticas pedagógicas na Educação Física escolar. Destaca o autor que a produção científica da Educação Física e as pesquisas empíricas, em especial na escola, praticamente não tiveram continuidade e aprofundamento, referindo-se às propostas interventoras tais como crítico-superadora, crítico-emancipatória e aulas abertas.

Diante desse contexto, consideramos importante compreender o lugar e o papel que a Didática vem assumindo nas práticas pedagógicas da Educação Física escolar, ou seja, por consideramos a Didática como elemento central na relação entre produção teórica e prática pedagógica, para tanto perguntamos se a concepção da Didática acompanhou as propostas teórico-metodológicas críticas.

O campo da Didática permite várias aproximações a partir de bases teóricas distintas e, muitas vezes, até contraditórias, nossa intenção é analisar como aparece esse conceito nos textos analisados para compreender que suas características de contrastes e contradições refletem o movimento de transformação pelo qual o 
campo da Didática vem passando, refletindo também um debate em torno de abordagens crítica da educação com proposições superdoras e emancipatórias.

Para desenvolver este estudo foi utilizada como método a análise bibliográfica de três artigos científicos, publicado nos dois, a partir da análise do conceito de "Didática da Educação Física escolar": "O Tempo e o Lugar de Uma Didática da Educação Física”, de Francisco Eduardo Caparroz e Valter Bracht (2007); "Por Uma Didática da Possibilidade: Implicações da Fenomenologia de Merleau-Ponty para a Educação Física”, de Mauro Betti, Elenor Kunz, Lísia C. Gonçalves de Araújo e Eliane Gomes da Silva, (2007) e "Didática da Educação Física Escolar e o processo lógico de apreensão do saber”, de Maristela da Silva Souza (2007).

Esse movimento na Educação Física sobre a existência de um problema da metodologia envolveu diversos pesquisadores, escolhemos os três artigos por suas distintas bases teóricas no campo crítico. Identificamos que apesar de críticos, apresentam nuances diferenciadas que serão destacadas a partir das estruturas conceituais emersas nos artigos e que orientaram este trabalho: a) Delimitação do objeto Didática, b) Concepção de Didática, c) Elementos didáticos limitadores, d) Cultura e Didática e e) Didática e intervenção pedagógica.

\section{Delimitação do objeto didática}

O texto de Bracht e Caparroz (2007) elegeu como objetivo central a preocupação quanto à produção acadêmica e os cursos de formação de professores de Educação Física na "hipertrofia" das discussões pedagógicas e "atrofia" das discussões da Didática da Educação Física escolar. Os autores verificam, nos cursos de formação de professores de Educação Física, a falta de aprofundamento de elementos estruturantes da Didática, que garantam aos futuros professores conhecimento técnico-pedagógico que subsidie as práticas pedagógicas, bem como a elaboração dos planos de ensino.

Os autores identificaram a partir de uma pesquisa na comunidade da Educação Física no Orkut, as dificuldades que os professores encontram para definir questões pedagógicas da Educação Física, tais como "o que ensinar”, "por que ensinar", "quando ensinar", "como ensinar", entre outras. É nesse sentido que Bracht e Caparroz (2007) apresentam como desafio verificar em que medida a produção científica e a formação de professores de Educação Física têm dialogado com as relações entre a pedagogia, Didática e a metodologia no ensino da Educação Física escolar.

Betti et al. (2007) apresentam implicações da fenomenologia de Merleau-Ponty para a Didática da Educação Física e elegeu os conceitos de "corpo próprio", "intencionalidade", "significação", "gesto”, "intersubjetividade” e "expressão”, com o propósito de compreender como estes conceitos se relacionam numa situação de ensino e aprendizagem na perspectiva do "Se-movimentar humano".

Os autores destacam que um dos problemas no trato da Didática da Educação Física escolar é o reducionismo voltado exclusivamente para a abordagem técnicoinstrumental, afastando-se de uma reflexão sobre os pressupostos estruturantes do método didático, da multidimensionalidade do processo de ensino-aprendizagem e das diferentes abordagens da prática pedagógica. Para superar esta visão reducionista de Didática, propõem uma Didática da possibilidade expressiva para as práticas 
pedagógicas da Educação Física, que tem como base teórica a fenomenologia de Merleau-Ponty.

O trabalho de Souza (2007) teve como objetivo situar, no contexto escolar, o conhecimento de que trata o âmbito da Didática da Educação Física, mostrando a sua relação com a lógica formal de apreensão do saber. Quando a autora se refere à lógica formal, está sinalizando que, no processo de ensino-aprendizagem, a Didática da Educação Física não se aproximou nem se apropriou de uma leitura mais crítica dos conhecimentos tratados no universo da Educação Física escolar. Destaca, ainda, que o tratamento destes conhecimentos está descolado de uma contextualização histórica, cultural, social, política e econômica. Para a superação desta realidade, a autora apresenta uma lógica dialética com base no materialismo histórico, que tem como propósito a apreensão do saber para a organização escolar e o desenvolvimento das práticas corporais.

\section{Concepção de didática}

A crítica que Bracht e Caparroz (2007) fazem ao movimento progressista dos anos 70, 80 e 90 refere-se ao afastamento da especificidade da Educação Física em nome das questões sociopolíticas mais gerais. Os autores ressaltam a necessidade de a Educação Física escolar investir na perspectiva de uma apropriação com a Didática, ou melhor, num deslocamento dos elementos estruturantes da Didática para o centro do debate pedagógico, promovendo uma (re) significação da Didática da Educação Física escolar em que devemos indagar sobre qual teoria pedagógica e Didática que vai mediar a prática.

Betti et al. (2007) entendem que o desafio da Didática da Educação Física escolar está centrado em superar o formalismo lógico, psicológico e técnico, desse reducionismo, ou seja, entendem e reconhecem que a Didática que tem norteado as práticas pedagógicas da Educação Física escolar pautou-se pela racionalidade técnicoinstrumental. Esta compreensão de Didática gerou um reducionismo do processo ensino e aprendizagem que, por sua vez, deveria buscar uma reflexão mais ampliada e crítica sobre os pressupostos estruturantes didáticos (conteúdos, contexto e sujeitos da aprendizagem), as diferentes abordagens da prática pedagógica e suas incidências concretas na dinâmica pedagógica.

Os autores acima defendem que a Didática da Educação Física escolar deve ir além da orientação dos conteúdos e métodos, devendo direcionar a interação educativa, atentando para as relações sociais e a comunicação humana. Para que isso se efetive, propõem que a Didática da Educação Física deve incorporar uma ontologia e uma epistemologia, enfim, aproximar-se de uma fundamentação filosófica para o que apostam os autores na fenomenologia, e aqui mais especificamente, recomendam uma "Didática da possibilidade expressiva" que leve em conta as significações e intencionalidades das experiências dos sujeitos do seu "Se-movimentar".

Souza (2007) entende que não tem como desvincular a Didática das questões de ordem social e econômica da sociedade atual. A autora faz uma opção teórica que defende a necessidade da compreensão de que Didática não pode estar descolada do fazer no mundo concreto, enquanto produção do conhecimento científico e ciência. 
Muito além de discutir especificamente a dimensão instrumental de Didática, a autora apresenta duas razões para pensar a Didática da Educação Física escolar e que, de certa forma, explicita uma nova concepção de Didática. A primeira razão é a aposta na cultura corporal como conteúdo, da idéia que deve conhecê-la como construção social; e a segunda razão é de reconhecer a importância da relação estabelecida entre Didática da Educação Física e ciência, ou seja, o processo de ensino e aprendizagem, bem como os aspectos didáticos, se expressa pelas opções científicas.

\section{Elementos didáticos limitadores}

Os autores dos três textos se referem à existência de uma série de interpretações dos problemas da Didática da Educação Física, que dificulta pensar uma Didática para superar os desafios das práticas pedagógicas da Educação Física escolar.

Bracht e Caparroz (2007) apontam que um desses problemas é a relação entre teoria e prática. Eles explicam que as teorias precisam ser modificadas pela própria prática, ou seja, a função da teoria é pensar sobre a prática procurando refletir sobre ela e projetar novas possibilidades de intervenções. Se a teoria funcionasse, seria apenas uma mera aplicação e o mérito seria da teoria que conduziu bem a prática. Mas o que acontece efetivamente no cotidiano do processo de ensino e aprendizagem da Educação Física escolar não é bem isso, e os autores corroboram que é interessante que a teoria na prática é outra, pois isto propõe que o professor da escola seja autor de sua prática e não mero reprodutor do que foi pensado pelos outros.

Para superar esta compreensão da teoria pedagógica, Bracht e Caparroz (2007) destacam o papel do professor, afirmando que ele não deve aplicar a teoria na prática e sim (re) construir (reinventar) sua prática com referência em ações/experiências e em reflexões/teorias. Para os autores, é fundamental que essa apropriação de teorias se dê de forma autônoma e crítica, em que o professor deve se reconhecer como ator da produção do conhecimento escolar.

Já para Betti et al. (2007), o problema da teoria e prática está relacionado aos fatores limitantes para pensar uma Didática na perspectiva de uma abordagem fenomenológica e a compreensão de alguns conceitos fundamentais que balizam a referida abordagem. Um destes conceitos delimitados pelos autores é a diferença entre o significado de "corpo objetivo" e "corpo próprio" ou "fenomenal". O "corpo objetivo" é o corpo considerado um objeto do mundo, como qualquer outro. No pensamento objetivo, a relação com o corpo não valoriza a experiência, o corpo se coloca apenas como uma ideia, uma imagem empobrecida. Já o "corpo próprio" ou "fenomenal" é o corpo resultante da experiência, é a função do corpo vivo, do corpo tal como é vivido.

O que confere significado a esse "corpo próprio" é o movimento, a partir das dimensões de temporalidade e transcendência. Neste sentido, corpo e movimento, para fenomenologia, estão intrinsecamente ligados, não existe corpo sem movimento e nem movimento sem corpo. O movimentar-se é a própria transcendência, cuja percepção associada a uma intencionalidade conduz à criação e à expressão.

Portanto, para os autores acima, um fator limitante da Didática da Educação Física no processo de ensino e aprendizagem é a desconsideração das intencionalidades do "Se-movimentar" do sujeito envolvido numa determinada experiência. 
Souza (2007) destaca que o principal fator limitante para pensar uma Didática para a Educação Física escolar é o desafio dos professores compreenderem que existe uma relação entre produção do conhecimento científico e as questões macrossociais, ou seja, esse processo é atravessado por visões de mundo e ideologias conflituosas e contraditórias e que de certa forma vão gerar movimentos de diferentes valores. Situada neste contexto, a Educação Física interpreta os diferentes paradigmas científicos, orientando sua Didática no trato dos conteúdos das práticas pedagógicas. Um paradigma que orienta as práticas pedagógicas da Educação Física escolar tem sido uma prática de cunho competitivo. Ao fazer esta opção, a autora acredita que os conteúdos incorporados nesta lógica reforçam a engrenagem das relações sociais capitalistas e, para superá-la, indica que o professor deve fazer uma leitura crítica da relação dialética estabelecida entre Ciência, Sociedade e Ensino Escolar.

\section{Cultura e a didática}

A cultura tem sido uma preocupação contemporânea que tem procurado entender os muitos caminhos que conduziram à evolução, a mudanças das sociedades. Neste texto, consideramos importante analisar este conceito devido sua relevância nas atuais pesquisas da Educação Física.

Para Bracht e Caparroz (2007), o conceito de cultura pode ser compreendido na medida em que se efetive uma discussão didático-pedagógica mais crítica para mediar às práticas pedagógicas da Educação Física escolar. Por isso, consideram fundamental compreender o fato de que não se pode basear a prática pedagógica, exclusivamente, em modelos ideais, em receitas universais, em verdades "absolutas", mas reconhecer que o conhecimento tratado no campo da Educação Física escolar é uma construção humana e histórica-cultural. Esta compreensão ajuda na reflexão da ação pedagógica. Neste sentido, em nossa análise, há uma crítica nesta perspectiva à valorização como resultado da produção história criada e recriada como o padrão da indústria cultural.

Para os autores, a intervenção pedagógica extrapola o paradigma da racionalidade instrumental, que gera um reducionismo da realidade. De acordo com eles, a prática pedagógica pressupõe um ideal de ser humano nas dimensões ética e política, significando que a produção do conhecimento na formação não pode estar desassociada das dimensões histórica e cultural.

Betti e outros (2007), ao optarem por uma Didática expressiva, mediada pela abordagem fenomenológica, vinculam o conceito de cultura à compreensão do "SeMovimentar", que se constitui com o diálogo entre homem e mundo. O diálogo homem/mundo pelo "Se-movimentar" pode conduzir à compreensão-de-mundopelo-agir, desde que o processo das práticas pedagógicas não se limite à imitação dos padrões de movimento pré-determinados e sinalizem para a busca da transcendência aprendida como possibilidade de criação. $O$ texto destaca a distinção entre gesto movimentante e gesto movimentado, em que o primeiro se constitui como um "Se-movimentar" originário, que o faz primeiramente existir para nós mesmos assim como para os outros; já o gesto movimentado, que é secundário porque já é adquirido, é passível de aprendizagem por imitação da forma, em detrimento da criação. Porém, tal entendimento apresenta, para os autores, um caráter ambíguo em relação 
à aprendizagem, por exemplo, dos gestos esportivos, pois se ao experimentarmos uma prática esportiva seríamos inéditos no plano da percepção, mas não o somos necessariamente no plano da cultura, no qual podemos nos repetir. Então, a fenomenologia vai se movimentar em relação ao conceito de cultura no campo da Educação Física na perspectiva de como entendem os autores apoiados em Merleau-Ponty, na aquisição cultural, na qual, para o sujeito que aprende pela primeira vez uma modalidade esportiva, os gestos e a percepção são inéditos e carregados de sentidos/significações, mas não o são para a cultura esportiva de alto rendimento, a qual pressupõe atividades de repetições para o aperfeiçoamento.

O conceito de cultura, no artigo de Souza (2007), aparece na medida em que a autora aponta para a necessidade de entender a relação estabelecida entre a Didática da Educação Física e a da ciência, compreendendo que, em um processo de ensino e aprendizagem, os aspectos didáticos expressam-se pelas opções científicas e pela maneira como é estabelecida a relação entre o conhecimento e a realidade. A Educação Física deve superar a lógica formal de ciências e contextualizar os princípios ideológicos, políticos, econômicos e culturais.

A crítica de Souza (2007) refere-se à prática pedagógica da Educação Física escolar pautada pelo viés competitivo, reforçando a lógica formal de ciência, em que o processo de ensino e aprendizagem é disseminado destituído de uma reflexão crítica e assimilado como se fosse construção "natural" e não construção humana. A preocupação da autora concentra-se no sentido de que este tipo de prática voltada para lógica formal é muito presente no âmbito da Educação Física escolar, que acaba promovendo sujeitos historicamente passivos, imobilizados em suas práticas sociais e silenciados no processo de construção do conhecimento que decorre de uma cultura elaborada.

Tal análise dialética entre sociedade e Didática da Educação Física fica melhor definida quando se define o conceito de cultura trabalhado pela autora. Neste sentido, entende-se cultura como processo histórico que tem a capacidade de narrar as tensões reais dos seres humanos, que produzem e reproduzem as relações sociais pelas quais se distinguem da natureza e diferenciam-se uns dos outros em diferentes classes sociais.

\section{Didática e intervenção pedagógica}

Bracht e Caparroz (2007) apontam alguns desafios para a intervenção na prática/ Didática da Educação Física: 1 - Reconhecer que as teorias da ação Didática pedagógica envolvem elementos que extrapolam o âmbito da chamada racionalidade técnica instrumental, que o universo da prática pedagógica é repleto de ambiguidades e que o modelo da racionalidade técnica é insuficiente para compreender a complexidade da prática pedagógica. Ao apostar num ensino pautado por uma Didática técnica, se abandona uma discussão mais ampliada e contextualizada da produção do conhecimento, e, em detrimento disso, instala-se e propaga-se o que Bracht e Caparroz (2007) denominam de uma "epistemologia da prática"; 2 - Potencializar aos professores das escolas se reconhecerem como capazes de pensar e teorizar suas práticas na perspectiva de promover um movimento permanente de (re) significar 
suas intervenções, isto significa o resgate da autoridade de professor, na perspectiva ontológica e epistemológica; 3 - Compreender a tensão permanente existente entre "dimensão da realidade" e "dimensão do que se idealiza" num processo de ensino. A realidade que a prática expressa deve alimentar a Didática por meio da reflexão num contínuo exercício de prática-reflexão-prática.

A produção de Betti et al. (2007) defende uma "Didática da possibilidade expressiva” para a Educação Física pautada na fenomenologia, em que as práticas pedagógicas nas aulas de Educação Física escolar se constituam pelo "Se-movimentar", apontando para alguns pressupostos teóricos a fim de alcançar esta condição.

Inicialmente, os autores destacam a necessidade de ampliação do entendimento do conceito de "Se-movimentar", pois por meio dele se pode conduzir os Homens à compreensão-de-mundo-pelo-agir, desde que o processo de ensino-aprendizagem não se restrinja à imitação de padrões de movimentos já fixados e busque a transcendência apreendida, que abre a possibilidade do encontro criativo ou inventivo com o mundo do movimento, o que altera a relação pedagógica dos professores com os estudantes, possibilitando um ambiente de criação pelo se movimentar.

O método didático da Educação Física com inspiração fenomenológica propõe possibilitar, a todos aqueles que iniciam uma prática corporal, a incorporação da experiência do "Se-movimentar" como um gesto "movimentante" e não como um "gesto movimentado", que é secundário, porque já foi adquirido, tendendo a levar para a aprendizagem por imitação da forma, em detrimento da ação das práticas corporais. Destaca-se que uma ação no universo dos esportes apresenta uma ambiguidade, podendo executar um gesto motor que pode ser inédito no plano da percepção, mas não o é no plano da cultura. Ou seja, a Didática fenomenológica não deve se tornar um "Discurso" sobre a cultura corporal de movimento, mas uma "Ação Pedagógica”, visto que a Didática da Educação Física escolar não deve se dissociar das práticas pedagógicas, das significações conceituais, das significações existenciais ou vice-versSouza (2007) propôs a superação da lógica formal que permeia os conteúdos e os conhecimentos das práticas pedagógicas da Educação Física, a partir de uma lógica dialética, que faz a mediação da Didática da Educação Física escolar a partir de uma compreensão de ciência na perspectiva histórica e cultural. Quando sinaliza a lógica dialética, a autora define a cultura a partir de aproximações do materialismo histórico dialético para a Didática da Educação Física como fundamento teórico metodológico na organização do trabalho pedagógico. Sugere a autora que a Didática da Educação Física, no trato do conhecimento, deve incluir a realidade para além da sala de aula, do pátio ou dos muros da escola, numa perspectiva crítica e acompanhando as mudanças históricas da realidade concreta.

Pensar uma Didática da Educação Física escolar na perspectiva da lógica dialética, para a autora, exige aos profissionais da Educação Física na escola reconhecer três aspectos fundamentais. $\mathrm{O}$ primeiro é entender o conhecimento no âmbito da cultura corporal relacionado com seu desenvolvimento, o que passa pela compreensão da relação dialética e histórica que constitui a cultura corporal de movimento. O segundo aspecto significa que entender dialeticamente a Educação Física como área de conhecimento que trata da cultura corporal implica entender a ciência como parte da 
construção histórica do ser humano. Nessa perspectiva, a prática pedagógica, no contexto da Didática da Educação Física, assume o compromisso de tratar os conteúdos da Educação Física como objetivações culturais das expressões corporais, produtos da relação de conhecimentos elaborados a partir de todos os campos científicos que sustentam o campo de atuação prática social da Educação Física. Isto significa, para a autora, que a Didática da Educação Física também exige apropriar-se das diferentes áreas de saberes científicos (ciências do esporte) que o sustentam (fisiologia, biomecânica, psicologia, sociologia...), sob um teorizar pedagógico dialeticamente construído. E o terceiro aspecto a se considerar é elevar os aspectos técnicos e valorativos das práticas corporais à compreensão de produção cultural.

\section{Conclusões provisórias}

Este estudo explicita a complexidade e a pluralidade de abordagens a respeito da Didática na Educação Física escolar, entre autores de abordagens críticas da Educação Física. Um dos indicadores desta análise é sobre a possibilidade de diferentes compreensões a partir de um mesmo objeto: no caso, a Didática. Neste sentido, identificaram-se alguns pontos comuns de discussão nos textos e alguns outros, se não divergentes, diferentes em sua perspectiva de abordagem e concepção epistemológica, mas que garantem o lugar da Didática como fundante para se conceber uma prática pedagógica crítica.

No que se refere às proximidades epistemológicas, os textos defendem que uma discussão sobre Didática da Educação Física pressupõe ir além da dimensão tradicional/técnico/instrumental de ciência e de educação sem desconsiderar a sua importância na organização e planejamento de um processo de ensino e aprendizagem. Porém, é fundamental reconhecer que a Didática pautada nos princípios das ciências naturais de caráter funcionalista não dá conta da complexidade que é o Ser Humano.

Outro aspecto destacado refere-se à função educativa da cultura corporal como conteúdo da Educação Física escolar, como apropriação do mundo, e que não deve estar descolado de um "saber fazer", que é a experiência motora, ou seja, a prática, mas uma prática (re) significada pela teoria. Nestes termos, o professor na escola deve conquistar sua autonomia intelectual no que diz respeito à produção do conhecimento, tomar como referência a realidade sociocultural, deve ser um sujeito "aberto" para o mundo, investindo na sua formação continuada.

No que se refere aos aspectos epistemológicos diferentes dos três textos, identificou-se, inicialmente, a respectiva opção teórica que trilhou suas discussões e apontamentos. Pode-se dizer que os três textos se localizam numa perspectiva/abordagem crítica e interventora, porém a partir de pressupostos teóricos ou matrizes teóricas diferentes. Bracht e Caparroz (2007) fazem a opção por uma abordagem histórico/ social. Betti et al. (2007) optam por uma abordagem filosófica, mais precisamente pela fenomenologia de Merleau-Ponty, apontando para uma aproximação desta abordagem com a Didática para a Educação Física, mediada pelo "Se movimentar humano.” Souza (2007), ao propor o conhecimento da Didática da Educação Física, demonstrando a sua relação com a lógica formal de apreensão do saber, faz a opção teórica pelo materialismo histórico dialético. 
Diante deste percurso, os artigos científicos em análise permitem a seguinte compreensão de Didática para a Educação Física escolar: para Bracht e Caparroz (2007), a Didática não pode ser vista como um mero instrumento técnico, e, sim, na perspectiva do professor de Educação Física como pesquisador de sua prática pedagógica, bem como o retorno à Didática, para o centro do debate pedagógico. Para isso é necessário conceber uma Didática pautada na relação prática-teoriaprática e na qual o professor deve escrever permanentemente sua prática pedagógica no sentido de (re) significá-la. Para Betti et al. (2007), a Didática tem a função de elucidar a prática pedagógica a partir de uma reflexão sobre os pressupostos e que deve buscar a superação de formalismos e reducionismos de seus elementos estruturantes da Didática, afirmando que a tarefa da Didática exige uma ontologia e uma epistemologia, enfim, uma fundamentação filosófica, a fenomenologia. Para tanto, apostam na Didática expressiva, em que os sujeitos de aprendizagem, sendo desafiados a experiências, que promovem a transcendência da compreensão-demundo-pelo agir, pelo "Se-movimentar" existe uma correspondência entre possibilidades perceptivas e possibilidades motoras. E, finalmente, para Souza (2007), a Didática da Educação Física escolar deve ser redimensionada a partir da organização do trabalho pedagógico, valorizando a cultura corporal como visceralmente imersa nas relações sócio-históricas, como uma prática social e como construção humana. Isto demanda que a Educação Física não desconsidere o papel da ciência e suas implicações na relação da realidade e conhecimento que envolve as orientações Didáticas das práticas pedagógicas.

A análise feita em relação às divergências decorrem da definição do objetivo da Educação Física e sua relação com a definição de Didática para os autores analisados. Em todos os textos, é perceptível um posicionamento crítico em relação à estrutura da sociedade atual e o papel fundamental da Educação Física no processo de formação humana e social. Porém, neste mesmo aspecto, há algumas diferenças entre eles. No caso do texto de Betti et al (2007) e do Bracht e Caparroz (2007) há a proposição de alterar os problemas/limites da realidade escolar. No caso do texto de Souza (2007), a possibilidade de superação da Didática está relacionada a mudanças na lógica pedagógica, pautada no materialismo histórico dialético que relaciona a Didática e a estrutura da sociedade capitalista. Portanto, para ela, é fundamental ter um projeto político pedagógico que objetiva a superação da organização social. Uma ação não está dissociada da outra. Em Betti et al (2007), por exemplo, o conceito de emancipação é importante para a Didática, na medida em que é uma proposição pedagógica que supere, ou seja, a formação que favoreça a emancipação contribui com a liberdade do ser humano para agir, pensar e sentir no mundo, dando a ele possibilidades de criar e recriar novas condições de movimento, não implicando um necessária superação da realidade social. Para o texto do Bracht e Caparroz (2007), esta condição entre o fazer nas aulas de Educação Física e o conceito está diretamente associado, incorporando uma Educação Física que critica o atual modelo de Didática e constrói ambientes pedagógicos de reflexão entre seus atores.

Essa parece ser uma das diferenças entre os autores analisados, pois é possível perceber que, a partir dessa posição política, diferenciam-se também conceitos, prá- 
ticas e proposições Didáticas para o processo pedagógico. Diferenciá-los entre si possibilita uma lucidez teórica em relação ao que cada uma das abordagens oferece impactando em uma prática pedagógica organizada a partir de uma Didática com temas, conteúdos, objetivos, avaliações e bibliografias coerentes, que reflitam uma atitude consciente de tomada de posição.

\title{
Didática of physical education industry: an understanding of scientific
}

\begin{abstract}
The objective of this paper is to understand the treatment and the role it has assumed a didactic teaching practices of physical education, and whether it followed the proposed methodological criticism. Was used as a method for analysis of three papers to be read unveiled conceptual frameworks that elucidate the theoretical and methodological-didactic. It was concluded after the interpretation of scientific articles that physical education must go beyond the reductionism of the technical-instrumental teaching and reassess the role of that approaching the pedagogical and epistemological.
\end{abstract}

Keywords: Curriculum - Physical Education - Knowledge Production.

\section{Didáctica industria de la educación física: una comprensión de la ciencia}

\section{Resumen}

El objetivo de este texto es comprender el tratamiento y el papel que la Didáctica viene asumiendo en las prácticas pedagógicas de la Educación Física escolar y si se siguieron las propuestas metodológicas críticas. Se utilizó como método a análisis de tres artículos científicos, cuya lectura desveló estructuras conceptuales que elucidaron los presupuestos teóricos y didáctico-metodológicos. Se concluye, posteriormente a la interpretación de los artículos científicos, que la Educación Física escolar debe superar el reduccionismo técnico-instrumental de la Didáctica y redimensionar su papel aproximándose a la dimensión pedagógica y epistemológica.

Palabras clave: Didáctica - Educación Física Escolar - Producción del Conocimiento.

\section{Referências}

BETTI, M. et al. Por uma Didática da possibilidade: implicações da fenomenologia de Merleau-Ponty para a Educação Física. Revista Brasileira de Ciências do Esporte, Colégio Brasileiro de Ciências do Esporte. Campinas, Autores Associados, v. 28, n. 2, p. 39-53, jan. 2007.

BRACHT, V.; CAPARROZ, F. E. O tempo e o lugar de uma Didática da Educação Física. Revista Brasileira de Ciências do Esporte, Colégio Brasileiro de Ciências do Esporte. Campinas, Autores Associados, v. 28, n. 2, p. 21-37, jan. 2007.

KUNZ, E. Transformação didático-pedagógica do esporte. Injuí, RS: Ed. Unijuí, 2003.

SOUZA, Maristela da Silva. Didática da educação física escolar e o processo lógico de apreensão do saber. Movimento Revista da Escola de Educação Física da UFRGS. Porto Alegre, v. 13, n. 3, p.181- 199, set./dez. 2007. 
Recebido em: 07-10-2009

Revisado em: 07-10-2009

Aprovado em: 25-10-2009

Endereço para correspondência

Paulo Carlan

Universidade Regional do Noroeste do Estado do Rio Grande do Sul

Instituto de Filosofia e Ciências Humanas

Rua São Francisco, 501, São Geraldo

CEP: 98700-000 - Ijui, RS - Brasil - Caixa-Postal: 560

E-mail:carlan@unijui.edu.br 